\title{
Knowledge and Attitude of Late Adolescent Girls regarding Polycystic Ovarian Syndrome
} Amira Mohamed Reda', Amal Ahmed Hassan Omran ${ }^{2}$, Hend Abdalla El Sayed ${ }^{3}$ and Amira Mohammed Salama ${ }^{4}$

(1) Nursing supervisor at Benha University Hospital, Egypt,(2)Professor of Obstetrics and Gynecological Nursing, Faculty of Nursing, Benha University, Egypt and (3,4)Assistant Professor of Obstetrics and Gynecological Nursing, Faculty of Nursing, Benha University, Egypt

\section{Abstract}

Background: Lack of knowledge regarding polycystic ovarian syndrome and poor lifestyle choices are considered to be the major factor leading to polycystic ovarian syndrome. Aim of study: Was to assess knowledge and attitude of late adolescent girls regarding polycystic ovarian syndrome. Design: Descriptive research design was utilized. Setting: This study was conducted at Technical Institute of Nursing at Benha University. Sampling: A purposive sample of 239late adolescent girls met the inclusion criteria. Tools of data collection: Two tools were used. I) A structured interviewing questionnaire which consisted of three parts: demographic characteristics, menstrual history of girls and knowledge of late adolescent girls regarding polycystic ovarian syndrome. II) Late adolescent girls`attitude towards polycystic ovarian syndrome. Results: More than half of late adolescent girls had unsatisfactory knowledge about polycystic ovarian syndrome. More than half of late adolescent girls had negative attitude toward polycystic ovarian syndrome. There was positive correlation between total knowledge and total attitude scores regarding polycystic ovarian syndrome (p-value 0.001). Conclusion: There was unsatisfactory knowledge and negative attitude regarding polycystic ovarian syndrome among late adolescent girls. Recommendation: Implementing an educational program about risk factors and preventive measures of polycystic ovarian syndrome among adolescent girls.

Key words: Attitude, Knowledge, Late Adolescent, Polycystic Ovarian Syndrome

\section{Introduction}

Polycystic Ovary Syndrome (PCOS) is a very complex syndrome, with typical hormonal and metabolic features. In adolescent girls, this condition shows particular characteristics which are in common with adult signs and symptoms, often making the diagnosis difficult (Capozzi et al., 2020). The prevalence based on Rotterdam criteria was $11.04 \%$, National Institute of Health was $3.39 \%$, and Androgen Excess and Polycystic Ovary Syndrome Society was $8.03 \%$ (Naz et al ., 2020).
Polycystic Ovary Syndrome is a lifelong disorder, commonly becomes manifest as puberty progresses, but its onset can occur later, during young adulthood. Clinical hallmarks are menstrual abnormalities and manifestations of hyperandrogenism, but the severity of the disorder is variable (Huddleston et al., 2020). The multifarious pathophysiology is attributed to a range of genetic and epigenetic changes, adrenal dysfunction, hypothalamic-pituitary dysfunction, insulin resistance, dyslipidemia, metabolic derangements, and environmental factors like sedentary lifestyle, atherogenic tendency, and belly fat deposition (Minocha, 2020). 


\section{$\underline{\text { Knowledge and Attitude of Late Adolescent Girls regarding Polycystic Ovarian Syndrome }}$}

Clinical features of PCOS include clinical hyperandrogenism in the form of hirsutism, acne, or alopecia. Menstrual irregularity encompasses primary or secondary amenorrhea, oligomenorrhea, irregular periods, and heavy menstrual bleeding. Clinical tests show polycystic ovarian morphology on ultrasound, and or metabolic derangement on blood testing, including insulin resistance, glucose intolerance, obesity and dyslipidaemia. There can be a marked heterogenicity in its clinical presentation (Deans, 2019).

The symptoms of PCOS usually begin at about the time of menarche, but postpubertal onset is also seen, usually as a result of environmental modifiers such as excess weight gain. Anovulatory symptoms (oligomenorrhea, dysfunctional uterine bleeding, and/or infertility) occur in about $75 \%$. Hirsutism affects about $60 \%$, acne affects $15 \%$ to $20 \%$, and androgenic alopecia about $5 \%$ of PCOS subjects. Obesity has been reported in $30 \%$ to $75 \%$ of PCOS subjects (Pfieffer, 2019).

In addition, PCOS has metabolic implications including insulin resistance, dyslipidaemia and abnormal glucose metabolism. Moreover, girls with PCOS also show a propensity for excess weight gain which exacerbates these symptoms. Cardiovascular risk factors such as chronic inflammation, oxidative stress and impaired fibrinolysis are increased with some evidence of a higher prevalence of cardiovascular disease. Furthermore, affected girls are more likely to experience moderate-to-severe depression and anxiety symptoms, low self-esteem, negative body image (Hachey et al., 2020).
Management of PCOS focuses on the menstrual abnormalities, symptoms of androgen excess, and associated metabolic changes. Weight loss through lifestyle change, use of hormonal contraceptive agents for menstrual regulation as well as androgen suppression, antiandrogens as adjuncts for hirsutism treatment, and insulin-sensitizing agents are common components of treatment (Huddleston et al., 2020).

Lack of knowledge and poor lifestyle choices are considered to be the major factor leading to this syndrome. Nurses are in unique position to create awareness regarding this syndrome. Informed choices and lifestyle management like weight loss, stress management are key factors in management of this disease (Sehar, 2020).

Nurses can have a positive impact on girls with PCOS through counseling and education. Provide support for adolescent girl dealing with negative self- image secondary to the physical manifestation of PCOS. Through education, help the girl understand the syndrome and its associated risk factors to prevent long -term health problems. Encourage the adolescent girl to make positive life style changes. Make referrals to local support groups to help the adolescent girl build the coping skill (Choragudi et al., 2018).

Moreover, nurses are well positioned to develop and implement PCOS care plans that are best presented as multifaceted, lifelong, educational approaches to wellness. A good plan will address nutrition education, meal planning, physical activity, mental and emotional health, and weight and stress reduction strategies to facilitate engagement, 
nurses can provide counseling with educational support in the form of electronic or written materials (Goetsch et al., 2020).

\section{Significance of the study}

Polycystic ovary syndrome is a significant public health issue with reproductive, metabolic, and psychological features. PCOS is the most common endocrine disorder with a prevalence of $6 \%-20 \%$ in women of reproductive age group (Witchel et al., 2019). Polycystic ovary syndrome affecting between 8 and $13 \%$ of women of reproductive age and $3-$ $11 \%$ of adolescent girls aged between 10 and 20 years diagnosed with the condition, according to the population studied and diagnostic criteria used (Peña et al., 2020). In Egypt, the prevalence of polycystic ovarian syndrome among Egyptian adolescent girls is $6.6 \%$ and those who are at high risk were $12.6 \%$. Thus, it is necessary to give attention to the importance of early diagnosis for this syndrome among this age group (Ibrahim et al., 2017).

Polycystic ovarian syndrome is the most common health problem during adolescence period, but the least understood and underdiagnosed one. The prevalence of this disorder is increasing rabidly worldwide. Adolescent girls have adequate knowledge about this syndrome (Haq et al., 2017). In addition, from clinical experience, the researcher observed that the late adolescent girls don't know polycystic ovarian syndrome. So, this study was conducted to assess knowledge and attitude of late adolescent girls regarding polycystic ovarian syndrome.

\section{Aim of the study}

The aim of this study was to assess knowledge and attitude of late adolescent girls regarding polycystic ovarian syndrome.

\section{Research questions:}

- What is the level of late adolescent girls' knowledge regarding polycystic ovarian syndrome?

- What is the level of late adolescent girls' attitude regarding polycystic ovarian syndrome?

- Is there relation between knowledge and attitude of late adolescent girls regarding polycystic ovarian syndrome?

\section{Subjects and Method}

\section{Research design}

Descriptive research design was utilized to fulfill the aim of the current study.

\section{Study setting}

This study was conducted in Technical Institute of Nursing at Benha University.

Sample type: A purposive sample.

\section{Sample Size}

A total of 239 late adolescent girl will be calculated using the following formula

$$
\mathrm{n}=\frac{\mathrm{N}}{1+\mathrm{N}(\mathrm{e})^{2}}
$$

Where $\mathrm{n}=$ required sample size

' $N$ ' is total number of all late adolescent

girls in first and second academic year at the Technical Institute of Nursing at

Benha University

$$
\begin{aligned}
& N=593 \text { student } \\
& ` \mathrm{e}^{`}=0,05 \\
& \mathrm{n}^{\prime}=239
\end{aligned}
$$

\section{Sample technique}

The researcher attended at the previous mentioned setting and the sample was collected from the first and second academic year (2019- 


\section{$\underline{\text { Knowledge and Attitude of Late Adolescent Girls regarding Polycystic Ovarian Syndrome }}$}

2020) and according to the inclusion criteria until the predetermined sample size was completed.

\section{Inclusion Criteria}

- Not married.

- Late adolescent girls between (17-19) years old.

- Accept to participate in the study.

\section{Tools of data collection:}

Two tools were used for data collection:

\section{Tool I: Self - administrated interviewing questionnaire sheet:}

This tool was developed by the researcher after reviewing of literature as (Devi et al., 2017); (Jayshree et al., 2017); (Patel, 2017). It was written in an Arabic language in the form of close and open-ended questions. It encompassed three parts:

Part (1): Included the demographic characteristics of late adolescent girls as age, educational class, residence, mother's education and job, father's education and job. As well as anthropometric measurement involved weight, height and body mass index and family history of polycystic ovarian syndrome.

Part (2): Included menstrual history of late adolescent girls (menarche age, frequency of menstruation, amount of blood loss, menstrual pain and menstrual duration).

Part (3): Included knowledge of late adolescent girls regarding polycystic ovarian syndrome. It consisted of 7 items (definition, predisposing risk factors, signs and symptoms, complications, diagnosis, prevention and treatment). As well as source of information regarding polycystic ovarian syndrome.

\section{Scoring system}

Each item was scored as complete correct answer (3), incomplete correct answer (2), while don't know answer (1). The total score for all items related to knowledge ranged from 121 points and categorized in two levels as followings:

- Unsatisfactory knowledge when total score was $<60 \%(1<13)$.

- Satisfactory knowledge when total score was $\geq 60 \%(13 \leq 21)$.

\section{Tool II: Late adolescent girls' attitude} towards polycystic ovarian syndrome sheet

This tool was developed by the researcher after reviewing of literature as (Starr, 2017); (Rizvi et al., 2017); (Darvda et al., 2020) to assess late adolescent girls' attitude towards polycystic ovarian syndrome. It consisted of 27 items.

\section{Scoring system}

Each item was judged according to a three point likart scale continuum from agree (3), neutural (2), and disagree (1). A total score ranged from 1-81 and was classified to the following:

- Negative attitude when total score was $<60 \%$ ( $1<49)$

- Positive attitude when total score was $\geq$ $60 \%(49 \leq 81)$

\section{Tools validity and reliability:}

Content validity of tools was assessed by three of expertise in obstetrics and 
gynecological nursing fields. The experts reviewed the tool for clarity of sentences, consistency and appropriateness of content. No modifications were done. Reliability of tools was done. Cronbach alpha for knowledge was 0.85 . A Cronbach alpha for attitude was 0.79 .

\section{Ethical considerations:}

An official permission from the selected study setting was obtained for the fulfillment of the study, the aim of the study was explained to each girl before applying the tools to gain confidence and trust, an oral consent was obtained from each girl to participate in the study and withdrawn when needed, the study was not having any physical, social or psychological risks on the participant, the data was collected and treated confidentially, each study subject was informed about time throughout the study.

\section{Pilot study}

The pilot study was conducted on $10 \%$ ( 24 adolescent girl) of the studied sample to assess clarity and applicability of tools as well as estimation of the time needed to fill questionnaire. No modification was done, adolescent girls in pilot study were included in the main study sample.

\section{Field work:}

The study started from the beginning of January, 2019 to the end of March, 2019 covering three months. The researcher visited the pre mentioned setting from 9 am to $1 \mathrm{pm}$, three days per week (Sunday, Tuesday and Thursday).

At the beginning of interview the researcher greeted each girl, introduced herself to each girl included in the study, explained the aim of the study and components of tools. The researcher assured that the data collected would be treated confidentially and used only for the purpose of the research. The researcher took an oral consent from participant prior data collection.

The researcher collected demographic characteristics and measured anthropometric measurement by measuring of weight (kilograms) and height (centimeters) which were converted into Body Mass Index ( $\mathrm{kg} / \mathrm{m} 2)$. Also, family history of polycystic ovarian syndrome and menstrual history and knowledge regarding polycystic ovarian syndrome were taken. The average time took 5-15mintues.

A questionnaire assessing late adolescent girls' attitude regarding polycystic ovarian syndrome was taken. The average time took $10 \quad-20$ minutes. The average time needed to complete tools ranged from 15-35 minutes. The average girls interviewed 22-30 per week.

\section{Limitation of the study:}

Sometimes interviewing nursing students was postponed as many nursing students were most of time busy with lectures during data collection.

\section{Results:}

Table (1): Shows that more than half of the late adolescent girls (58.6\%) aged 19 years old with the mean age $18.47 \pm 0.52$ years. More than half of them $(55.2 \%)$ were in the second educational class and nearly three quarters of them $(74.1 \%)$ were living in rural area. More than one third of the late adolescent girls' mothers $(38.5 \%)$ had secondary educational level and less than two thirds (61. 1\%) were not working. More than half of the late adolescent girls' fathers $(59.0 \%)$ had secondary education and the majority of them (95.4\%) were working. 
Table (2): Shows that, the mean height and weight of the late adolescent girls were $160.33 \pm 5.25 \mathrm{~cm}, \quad 62.53 \pm 10.734 \mathrm{~kg}$ respectively, and the mean body mass index was $24.39 \pm 4.59 \mathrm{~kg} / \mathrm{m} 2$.

Table (3): Shows that there was positive correlation between total knowledge and total attitude scores regarding polycystic ovarian syndrome $\mathrm{p}$-value (0.001).

Table (4): Shows that there was a highly statistical significant relation between late adolescent girls' level of knowledge about polycystic ovarian syndrome and demographic characteristics (age, educational class, residence, mother's education, mother's job, and father's education) ( $\mathrm{P} \leq 0.05)$. Meanwhile, there was no statistical significant relation between level of knowledge and father's job.

Table (5): Shows that there was a highly statistical significant relation between late adolescent girls' level of attitude about polycystic ovarian syndrome and demographic characteristics (age, educational class, residence , mother's education, mother's job, father's education $)(\mathrm{P} \leq 0.01)$. While there was a statistical significant relation between late adolescent girls' level of attitude and father's job $(\mathrm{P} \leq 0.05)$. 
Table (1): Distribution of the late adolescent girls according to demographic characteristics (n=239)

\begin{tabular}{|c|c|c|}
\hline Demographic characteristics & No. & $\%$ \\
\hline \multicolumn{3}{|l|}{ Age $($ years $)$} \\
\hline 18 & 99 & 41.4 \\
\hline 19 & 140 & 58.6 \\
\hline \multicolumn{3}{|c|}{$18.47 \pm 0.52$} \\
\hline \multicolumn{3}{|l|}{ Educational class } \\
\hline First & 107 & 44.8 \\
\hline Second & 132 & 55.2 \\
\hline \multicolumn{3}{|l|}{ Residence } \\
\hline Urban & 62 & 25.9 \\
\hline Rural & 177 & 74.1 \\
\hline \multicolumn{3}{|l|}{ Mother's education } \\
\hline Illiterate & 38 & 15.9 \\
\hline Basic education & 26 & 10.9 \\
\hline Secondary education & 92 & 38.5 \\
\hline High education & 83 & 34.7 \\
\hline \multicolumn{3}{|l|}{ Mother's job } \\
\hline Working & 93 & 38.9 \\
\hline Not working & 146 & 61.1 \\
\hline \multicolumn{3}{|l|}{ Father's education } \\
\hline Basic education & 24 & 10.0 \\
\hline Secondary education & 141 & 59.0 \\
\hline High education & 74 & 31.0 \\
\hline \multicolumn{3}{|l|}{ Father's job } \\
\hline Working & 228 & 95.4 \\
\hline Not working & 11 & 4.6 \\
\hline
\end{tabular}

Table (2): Distribution of the late adolescent girls according to Anthropometric measurements $(\mathbf{n}=239)$

\begin{tabular}{|l|c|c|c|}
\hline Anthropometric measurements & Minimum & Maximum & Mean \pm SD \\
\hline Height $(\mathrm{cm})$ & 145 & 168 & $160.33 \pm 5.25$ \\
\hline Weight $(\mathrm{kg})$ & 45 & 82 & $62.53 \pm 10.734$ \\
\hline Body Mass Index $(\mathrm{kg} / \mathrm{m} 2)$ & 17.57 & 34.13 & $24.39 \pm 4.59$ \\
\hline
\end{tabular}


$\underline{\text { Knowledge and Attitude of Late Adolescent Girls regarding Polycystic Ovarian Syndrome }}$

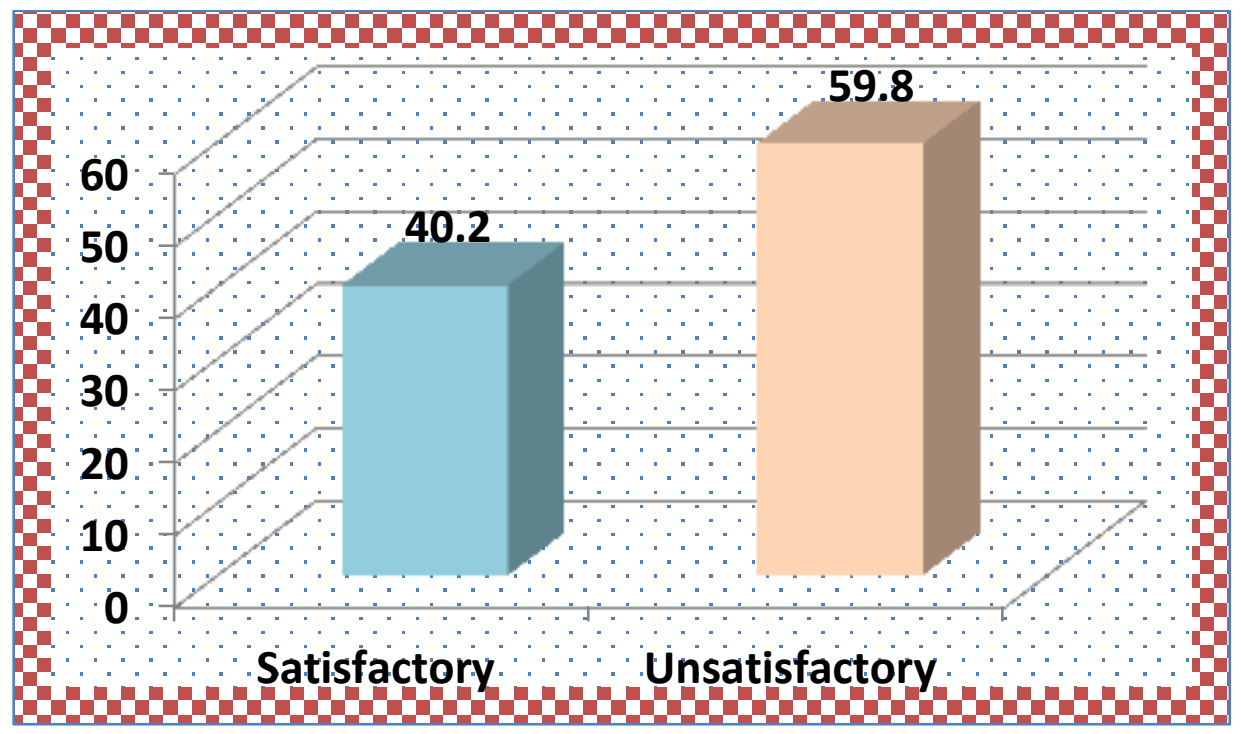

Figure (1): Distribution of the late adolescent girls according to level of total knowledge about polycystic ovarian syndrome

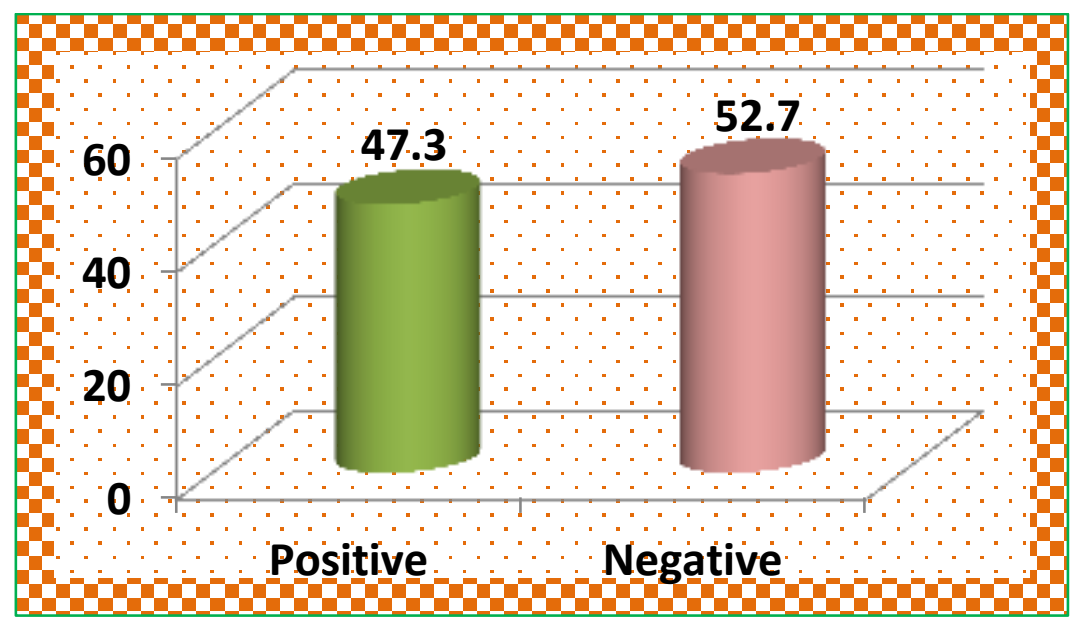

Figure (2): Distribution of the late adolescent girls regarding level of total attitude toward polycystic ovarian syndrome

Table (3): Correlation between late adolescent girls' total knowledge and total attitude scores regarding polycystic ovarian syndrome $(n=239)$

\begin{tabular}{|l|c|c|}
\hline Variable & \multicolumn{2}{|c|}{ Total knowledge score } \\
\cline { 2 - 3 } & $\mathbf{r}$ & P value \\
\hline Total attitude score & 0.413 & $0.000 * *$ \\
\hline
\end{tabular}

**A highly statistical significant difference $(\mathrm{P} \leq 0.001)$ 
Table (4): Relation between the late adolescent girls' demographic characteristics and level of knowledge about polycystic ovarian syndrome $(\mathbf{n}=239)$

\begin{tabular}{|c|c|c|c|c|c|c|}
\hline \multirow{2}{*}{\begin{tabular}{|l}
\multicolumn{1}{|c|}{ Level of knowledge } \\
Demographic \\
characteristics
\end{tabular}} & \multicolumn{2}{|c|}{$\begin{array}{c}\text { Satisfactory } \\
n=96\end{array}$} & \multicolumn{2}{|c|}{$\begin{array}{c}\text { Unsatisfactory } \\
n=143\end{array}$} & \multirow[t]{2}{*}{$\mathbf{X}^{2}$} & \multirow[t]{2}{*}{ P-value } \\
\hline & No & $\%$ & No & $\%$ & & \\
\hline \multicolumn{7}{|l|}{ Age (years) } \\
\hline 18 & 14 & 14.6 & 85 & 59.4 & 47.633 & $0.000 * *$ \\
\hline 19 & 82 & 85.4 & 58 & 40.6 & & \\
\hline \multicolumn{7}{|l|}{ Educational class } \\
\hline First & 33 & 34.4 & 74 & 51.7 & 7.011 & $0.008^{*}$ \\
\hline Second & 63 & 65.6 & 69 & 48.3 & & \\
\hline \multicolumn{7}{|l|}{ Residence } \\
\hline Urban & 53 & 55.2 & 9 & 6.3 & 71.535 & $0.000 * *$ \\
\hline Rural & 43 & 44.8 & 134 & 93.7 & & \\
\hline \multicolumn{7}{|l|}{ Mother's education } \\
\hline Illiterate & 6 & 6.3 & 32 & 22.4 & & \\
\hline Basic education & 10 & 10.4 & 16 & 11.2 & 16.418 & $0.001 *$ \\
\hline Secondary education & 35 & 36.5 & 57 & 39.8 & & \\
\hline High education & 45 & 46.8 & 38 & 26.6 & & \\
\hline \multicolumn{7}{|l|}{ Mother's job } \\
\hline Working & 64 & 66.7 & 29 & 20.3 & 51.955 & $0.000 * *$ \\
\hline Not working & 32 & 33.3 & 114 & 79.7 & & \\
\hline \multicolumn{7}{|l|}{ Father's education } \\
\hline Basic education & 15 & 15.6 & 9 & 6.3 & & \\
\hline Secondary education & 29 & 30.2 & 112 & 78.3 & 55.421 & $0.000 * *$ \\
\hline High education & 52 & 54.2 & 22 & 15.4 & & \\
\hline \multicolumn{7}{|l|}{ Father's job } \\
\hline Working & 90 & 93.7 & 138 & 96.5 & 0.992 & 0.319 \\
\hline Not working & 6 & 6.3 & 5 & 3.5 & & \\
\hline
\end{tabular}

*A statistical significant difference $(P \leq 0.05)$

**A highly statistical significant difference $(\mathrm{P} \leq \mathbf{0 . 0 0 1})$ 
Knowledge and Attitude of Late Adolescent Girls regarding Polycystic Ovarian Syndrome

Table (5): Relation between of the late adolescent girls' demographic characteristics and level of attitude about polycystic ovarian syndrome $(n=239)$

\begin{tabular}{|c|c|c|c|c|c|c|}
\hline \multirow{2}{*}{\begin{tabular}{|l} 
Level of attitude \\
Demographic \\
characteristics
\end{tabular}} & \multicolumn{2}{|c|}{$\begin{array}{l}\text { Positive } \\
n=113\end{array}$} & \multicolumn{2}{|c|}{$\begin{array}{l}\text { Negative } \\
n=126\end{array}$} & \multirow[t]{2}{*}{$\mathrm{X}^{2} / \mathrm{FET}$} & \multirow[t]{2}{*}{ P-value } \\
\hline & No & $\%$ & No & $\%$ & & \\
\hline \multicolumn{7}{|l|}{ Age ( years) } \\
\hline 18 & 16 & 14.2 & 83 & 65.9 & 65.659 & $0.000 * *$ \\
\hline 19 & 97 & 85.8 & 43 & 34.1 & & \\
\hline \multicolumn{7}{|l|}{ Educational Class } \\
\hline First & 32 & 28.3 & 75 & 59.5 & 23.461 & $0.000 * *$ \\
\hline Second & 81 & 71.7 & 51 & 40.5 & & \\
\hline \multicolumn{7}{|l|}{ Residence } \\
\hline Urban & 57 & 50.4 & 5 & 4.0 & 66.974 & $0.000 * *$ \\
\hline Rural & 56 & 49.6 & 121 & 96.0 & & \\
\hline \multicolumn{7}{|l|}{ Mother's education } \\
\hline Illiterate & 6 & 5.3 & 32 & 25.4 & & \\
\hline Basic education & 10 & 8.8 & 16 & 12.7 & 25.089 & $0.000 * *$ \\
\hline Secondary education & 44 & 38.9 & 48 & 38.1 & & \\
\hline High education & 53 & 46.9 & 30 & 23.8 & & \\
\hline \multicolumn{7}{|l|}{ Mother's job } \\
\hline Working & 65 & 57.5 & 28 & 22.2 & 31.229 & $0.000 * *$ \\
\hline Not working & 48 & 42.5 & 98 & 77.8 & & \\
\hline \multicolumn{7}{|l|}{ Father's education } \\
\hline Basic education & 11 & 9.7 & 13 & 10.3 & 43.348 & $0.000 * *$ \\
\hline Secondary education & 44 & 38.9 & 97 & 77.0 & & \\
\hline High education & 58 & 51.4 & 16 & 12.7 & & \\
\hline \multicolumn{7}{|l|}{ Father's job } \\
\hline Working & 111 & 98.2 & 117 & 92.9 & $3.917 £$ & $0.048^{*}$ \\
\hline Not working & 2 & 1.8 & 9 & 7.1 & & \\
\hline
\end{tabular}

*A statistical significant difference $(P \leq 0.05)$

£ FET: Fisher Exact Test

**A highly statistical significant difference $(\mathrm{P} \leq 0.001)$

\section{Discussion}

Adolescents form a large section of population. Adolescent girls have to be focused more as it is a period of rapid physical growth, sexual, physiological, and psychological changes. Habits and behavior picked up during adolescence have lifelong impact (Teede et al., 2018). Polycystic ovarian syndrome is the most common endocrinologic disorders during adolescence. Early recognition and prompt treatment of PCOS in adolescents is important 
to prevent long term complications (Peet et al., 2020).

The aim of current study was to assess knowledge and attitude of late adolescent girls regarding polycystic ovarian syndrome. The findings of the current study will be discussed under four main parts including general characteristics of the late adolescent girls, late adolescent girls' knowledge regarding polycystic ovarian syndrome, late adolescent girls' attitude regarding polycystic ovarian syndrome, correlation and relation between the study variables.

General characteristics of the late adolescent girls, regarding age, the results of the current study showed that more than half of the late adolescent girls aged 19 years old with the mean age $18.47 \pm 0.52$ years. This finding was supported with Devi, (2017) who conducted a study on ovarian syndrome among students of selected nursing institute of Gangtok and reported that $36(60 \%)$ adolescent girls were in the age 19 years. In the same line these findings came in harmony wih Haseena, (2019) who conducted study about level of knowledge on polycystic ovarian syndrome among adolescent girls and found that the majority of adolescents girls were at 19 years. This might be because most of student in technical institute of nursing graduated from secondary school at the age of 18-19.

Regarding residence, the results of the current study showed that nearly three quarters of the late adolescent girls were living in rural area. This finding was supported with Rawat et al., (2017) who conducted a Structured teaching program on knowledge about polycystic ovarian syndrome among adolescent girls and reported that all adolescent girls (100\%) participants were belonging to rural area. This might be because most of student in faculty of nursing live around Benha city which is considered a rural area.

Concerning mother and father education, the results of current study illustrated that more than one third of the late adolescent girls' mothers had secondary educational level and more than half of the late adolescent girls' fathers had basic educational level and the majority of the late adolescent girls' fathers were working. these finding was in disagreement with Atiqulla et al., (2019) who conducted an interventional study on effectiveness of structured education programme in improving the knowledge of polycystic ovarian syndrome among female students and they founded that almost half (47.8\%) of the of participant's mothers had primary education. Majority $(59.57 \%)$ of the participant's fathers had intermediate education.

\section{Concerning anthropometric} measurements, the mean height and weight and the mean body mass index of the late adolescent girls the results of the present study showed that, the mean height and weight of the studied students were $160.33 \pm 5.25 \mathrm{~cm}, 62.53 \pm$ $10.734 \mathrm{~kg}$ respectively, and the mean body mass index was $24.39 \pm 4.59 \mathrm{~kg} / \mathrm{m}^{2}$. These findings was in agreement with Darvda et al., (2020) who conducted a study about knowledge, attitude and practice towards exercise in young females diagnosed with polycystic ovary syndrome and reported that the mean height $(\mathrm{cm})$ of the population was 160.98 and the mean weight $(\mathrm{kg})$ was 59.75 . 


\section{$\underline{\text { Knowledge and Attitude of Late Adolescent Girls regarding Polycystic Ovarian Syndrome }}$}

Concerning total knowledge about polycystic ovarian syndrome, the findings of the present study showed that more than half of the late adolescent girls had unsatisfactory knowledge about polycystic ovarian syndrome. This lack of knowledge regarding PCOS may be due to that late adolescent girls did not receive the needed scientific information about PCOS.

This result is supported by, El Sayed and El Sayed, (2019) who conducted a study of "Screening for Polycystic Ovarian Syndrome and Effect of Health Education on its Awareness among Adolescents: A Pre-Post Study" The study revealed that there is inadequate knowledge regarding polycystic ovarian syndrome before educational sessions. Also these results were agreed with Haseena et al., (2019) who founded that majority (77\%) of adolescent girls had inadequate total knowledge about polycystic ovarian syndrome.

In the same line, this result was supported by, Upadhye and Shembekar, (2017). Who conducted a study on awareness of PCOS (polycystic ovarian syndrome) in adolescent and young girls and revealed that all studied girls had inadequate knowledge regarding polycystic ovarian syndrome. Also, this finding was in agreement with Haq et al., (2017) who conducted a study about prevalence and knowledge of polycystic ovary syndrome (PCOS) among female science students of different public universities of Quetta and revealed that the most of the female student had low knowledge about polycystic ovarian syndrome.

Moreover, the current study results were supported by Gupta et al.,(2018). Who conducted a cross sectional study of polycystic ovarian syndrome among young women in Bhopal and showed that before program the majority of students had inadequate knowledge, whereas $(9.17 \%)$ of them had moderate knowledge.

Concerning total attitude toward polycystic ovarian syndrome the results of the present study showed that more than half of the late adolescent girls had negative attitude toward polycystic ovarian syndrome. This may be due to unsatisfactory knowledge of late adolescent girls leads to negative attitude toward PCOS.

These results came in harmony with Chauhan et al., (2021) who conducted a study to evaluate the effectiveness of structured teaching program on knowledge regarding polycystic ovarian syndrome and related infertility among female students in Isabella Thoburn College at Lucknow and reported that nearly half of female students had negative attitude toward polycystic ovarian syndrome. Also these findings was in agreement with Hajivandi et al., (2018) who conducted a comprehensive interventional program for promoting eating behaviors in adolescent girls with polycystic ovarian syndrome and reported that less than two thirds of the studied adolescent girls with polycystic ovarian syndrome had negative attitude toward polycystic ovarian syndrome and more than one third of them had positive attitude toward polycystic ovarian syndrome.

Conversely these findings were disagreed with Kurdi et al., (2021) who conducted "Educational Program: It's Effect on Knowledge and Lifestyles among Paramedical 
Students with Polycystic Ovarian Syndrome (PCOS)" and indicated that less than one third of the studied students had negative attitude toward polycystic ovarian syndrome. This may be due to that the late adolescent girls were paramedical students and may have sufficient knowledge that leads to positive attitude.

Moreover, the results of the present study showed that there was a positive correlation between total knowledge and total attitude scores regarding polycystic ovarian syndrome. This may be due to when adolescents had correct and sufficient knowledge, this will drived them to positive attitude direction.

These results came in harmony with Monterio et al., (2021) who conducted a study to assess the effectiveness of structured teaching program regarding knowledge on polycystic ovarian syndrome among the adolescents of selected PU College in Mangaluru and reported that there was statistically significant relation between knowledge and attitude among nursing students. Also these findings was in agreement with Hajivandi et al., (2018) who reported that total knowledge adolescent girls about polycystic ovarian syndrome have positive effects on attitude.

On the other hand, these results were in disagreement with Karkar et al., (2019) who conducted a study to assess the knowledge regarding polycystic ovarian syndrome among undergraduate students in selected colleges of Pune city and indicated that there is no relation between students' knowledge about polycystic ovarian syndrome and attitude.

As regards relation between the late adolescent girls' demographic characteristics and level of knowledge about polycystic ovarian syndrome, the results of the present study showed that there was a highly statistical significant relation between studied late adolescent girls' level of knowledge about polycystic ovarian syndrome and demographic characteristics (age, educational class, residence, mother's education, mother's job, and father's education) $(\mathrm{P} \leq 0.05)$. Meanwhile, there was no statistical significant relation between level of knowledge and father's job. This may be due to when mother had high education she can lead the entire family toward adopting correct information and increase level of knowledge of the girls.

This finding is supported with Devi, (2017) who showed that there was highly statistically significant relationship between age of the students and mother education with level of knowledge at pre-test. Also, these findings came in harmony with Sowmya and Anitha (2017): who conducted a clinical study of polycystic ovarian syndrome (PCOS) in tertiary care centre and showed that there was relation between the ages in years with pre-test knowledge scores.

Moreover, the findings contraindicated with Atiqulla et al., (2019) who founded that there was no statistically significant relation between total knowledge score and socio demographic characteristics (age, , occupation, type of the family, residence, socioeconomic status) at both pre and post implementation phases.

Regarding relation between of the late adolescent girls' demographic characteristics and level of attitude about polycystic ovarian syndrome the results of the present study 


\section{Knowledge and Attitude of Late Adolescent Girls regarding Polycystic Ovarian Syndrome}

showed that there was a highly statistical significant relation between late adolescent girls' level of attitude about polycystic ovarian syndrome and demographic characteristics ( age, educational class, residence, mother's education, mother's job, father's education ). While there was a statistical significant relation between late adolescent girls' level of attitude and father's job. This result was in agreement with Selvaraj, (2020) who conducted an implementation of an awareness program and lifestyle intervention on polycystic ovarian syndrome among adolescent school girls in India and reported that there was a statistical significant relation between studied adolescent school girls' attitude about polycystic ovarian syndrome and demographic data.

In the same line these result supported by Shrivastava and Jagdev, (2019) who conducted a study to assess the effectiveness of self-instructional module on knowledge regarding polycystic ovarian syndrome among B. Sc. nursing students of selected nursing college and reported that the demographic data showed significant relation with the nursing student attitude regarding polycystic ovarian syndrome. In another hand, these results were in disagreement with Karkar et al., (2019) who indicated that there is no relation between student's attitude regarding polycystic ovarian syndrome and the age.

\section{Conclusion}

More than half of the late adolescent girls had unsatisfactory knowledge about polycystic ovarian syndrome. Also, more than half of the late adolescent girls had negative attitude toward polycystic ovarian syndrome. There was a positive correlation between total knowledge score and total attitude score. Therefore, the aim of the study was achieved and the study questions were answered.

\section{Recommendations}

- An intensive educational program should be implemented to increase girls' knowledge regarding symptoms of polycystic ovarian syndrome.

- Implementing an educational program about risk factors and preventive measures of polycystic ovarian syndrome among adolescent girls.

- Encourage adolescent girls to avoid weight gain through periodic exercise, good balanced diet and healthy habits.

\section{Further researches:-}

- Assess lifestyle of adolescent girls with polycystic ovarian syndrome.

- Assess the existing nurses' knowledge about non pharmacological measures for relieving symptoms of polycystic ovarian syndrome.

- Replication of the study on a large sample for generalizing the findings.

\section{References}

Atiqulla S., Gulam S., Ghufram A., Bana M., Raghad H., (2019). An Interventional Study on Effectiveness of Structured Education Programme in Improving the Knowledge of Polycystic Ovarian Syndrome among Female Students. IJSR.;5(1):1659-61.

Capozzi A., Scambia G., and Lello S., Capozzi A., Scambia G., and Lello S., (2020). Polycystic ovary syndrome (PCOS) and adolescence: How can we manage it?, 
European Journal of Obstetrics \& Gynecology and Reproductive Biology, 250: 235-240.

Chauhan P., Siddiqui M. I., and Chauhan, A. S., (2021). A study to evaluate the effectiveness of structured teaching programme on knowledge regarding polycystic ovarian syndrome and related infertility among female students in Isabella Thoburn College at Lucknow. Asian Journal of Nursing Education and Research, 11(1), 71-78.

Choragudi S., Rayapu V., and Jonnalagadda M.,(2018). A Study To Assess The Knowledge Of Nursing College Students Regarding Polycystic Ovarian Syndrome In Selected College At Guntur District, Andhra Pradesh, International Journal of Advances in Nursing Management, 6(3): 210-214.

Darvda P.V., Nagarwala R.M., Shyam A.K., and Sancheti P.K., (2020). Knowledge, attitude and practice towards exercise in young females diagnosed with polycystic ovary syndrome. Indian $\mathbf{J}$ Obstet Gynecol Res 2020;7(3):369-373.

Deans R., (2019). Polycystic Ovary Syndrome in Adolescence, Med Sci (Basel), 7(10), 101. Available at: https://doi.org/10.3390/medsci7100101.

Devi B., Karma D.B., Chemi D.B., Dechen S., Deepika C., (2017). Ovarian syndrome among students of selected nursing institute of Gangtok, East Sikkim International Journal of Current Research, 9, (11), 61458-61464.

El Sayed M.L.S., El Sayed M.LM., and Michael C.G., (2020). "Screening for Polycystic Ovarian Syndrome and Effect of Health Education on its Awareness among Adolescents: A Pre-Post Study", International Journal of Nursing Education, 12(4), 228-236.

El-Bana H.M., and Abd Elhakm M.A., (2018). Effect of Simulation Based Training on Maternity Nurses' Performance and Self- confidence Regarding Primary Postpartum Hemorrhage Management. American Journal of Nursing Research; 6 (6), 388-397. DOI: 10.12691/ajnr-6-6-6.

Goetsch L.A., Kimelman D., and Woodruff K.T., (2020). Polycystic Ovary Syndrome, Fertility Preservation and Restoration for Patients with Complex Medical Conditions, Springer International Publishing, 1st ed, pp 231-248.

Gupta M., Singh D., Toppo M., Priya A., Sethia S., Gupta P., (2018). A cross sectional study of polycystic ovarian syndrome among young women in Bhopal, Central India. Int J Community Med Public Health; 5: 95-100.

Hachey L.M., Kroger-Jarvis M., PavlikMaus T., and Leach R., (2020). Clinical Implications of Polycystic Ovary Syndrome in Adolescents. Nursing for women's health, 24(2):115-126.

Hajivandi L., Noroozi M., Mostafavi F., and Ekramzadeh M., (2018). A comprehensive interventional program for promoting eating behaviors in adolescent girls with polycystic ovarian syndrome (PCOS): protocol for a mixed methods study. Reproductive health, 15(1), 1-8.

Haq N., Khan Z., Riaz S., Nasim A., Shahwani R., Tahir M., (2017). Prevalence and knowledge of polycystic ovary syndrome (PCOS) among female science students of different public universities of Quetta, Pakistan. Imperial Journal of Interdisciplinary Research (IJIR), 3(6), 2454-1362.

Haseena B., (2019). Level of Knowledge on Polycystic Ovarian Syndrome among Adolescent Girls.J Nurse Midwifery Matern Health;5(3):111-114.

Huddleston G. H., Quinn M., and Gibson M., (2020). Polycystic Ovary Syndrome and 
Hirsutism, Nelson Textbook of Pediatrics, 1st ed, pp 2857-2861.

Ibrahim M.S, Elsayed A.Y., Reyad E.R., and Azzam F.H., (2017). Screening of polycyctic ovarian syndrome among adolescent girls at Cairo University, The MalasianJournal of Nursing, 9 (1):16-20.

Jayshree S., Rayapu V., and Jonnalagadda M.,(2017). A study to assess the knowledge of nursing college students regarding polycystic ovarian syndrome in selected college at Guntur District, Andhra Pradesh, International Journal of Advances in Nursing Management, 6(3): 210-214.

Karkar M., Abraham F.A., Joseph D., Thomas A. S., Bharam D., and Mathew B.M., (2019).A study to assess the knowledge regarding polycystic ovarian syndrome among undergraduate students in selected colleges of Pune city, The Pharma Innovation Journa; 8(6): 192-194.

Kurdi Z. R. A., Fahmy N. M., Mohasb S. H., and Abd Alhamid N., (2021). "Educational Program: Its Effect on Knowledge and Lifestyles among Paramedical Students with Polycystic Ovarian Syndrome (PCOS)", Medico Legal Update, 21(3):58-69.

Minocha N., (2020). Polycystic Ovarian disease or Polycystic Ovarian Syndrome: how to identify and manage_ areview, Arch Pharm Pract, 11 (2) : 102-106.

Monterio S., Anusree G., Anusree K. T., Prasad A. N., Tom R., David L., and Devasya S., (2021). A Study to assess the effectiveness of structured teaching programme regarding knowledge on polycystic ovarian syndrome among the adolescents of selected PU College in Mangaluru, Asian Journal of Nursing Education and Research, 11(2), 213216.
Naz M.S.G, Tehrani F.R., Lak B., Mohammadzadeh., Farnaz ., Nasiri., Nasiri, Malihe; et al. (2020). Quality of life and emotional states of depression, anxiety and stress in adolescents with polycystic ovary syndrome: a cross-sectional study. Psychology Research and Behavior Management; Macclesfield, (13): 203-209.

Patel K., (2017). Effectiveness of planned teaching program on polycystic ovarian syndrome in terms of knowledge and attitude among adolescent girl in Ahmedabad. J Nur Today.;2(3): 50-60.

Peet P.K., Leathem L.D., Currin D.L, and Karlsgodt K.H., (2020). Polycystic ovary syndrome in adolescents. Best Practice \& Research Clinical Obstetrics \& Gynaecology, 48:103-114.

Peña A.S., Witchel S.F., Hoeger K.M., Oberfield S.E., Vogiatzi M.G., Misso M., and Teede, H., (2020). Adolescent polycystic ovary syndrome according to the international evidence-based guideline. BMC medicine, 18(1), 1-16.

Pfieffer M.L., (2019). Polycystic ovary syndrome: An update, Europe PMC, 49(8):3440.

Rawat S., Gomathi B., Laxmi K., Mahalingam V., (2017). Structured teaching programme on knowledge about polycystic ovarian syndrome among adolescent girls. Int $\mathbf{J}$ Res Med Sci; 5: 5004-5008.

Rizvi M., Abbas A., Tanwir S., Sabah A., Ali Z.M., Sundrani M.M., Arif S., Afzal A., Mir H.A., (2017). Perception and attitude of patients regarding polycystic ovarian syndrome (PCOS) in Ttertiary care hospitals of Pakistan a survey based study, International Journal of Pharmacy \& Therapeutics, 5(3), 2014, 147-152. 
Sehar S., (2020). Assessment of Knowledge regarding Polycystic Ovary Syndrome (PCOS) among nursing students, International Journal of Nursing \& Midwifery Research, 7:(3) 14-30. Selvaraj V., (2020). Implementation of an awareness program and lifestyle intervention on polycystic ovarian syndrome among adolescent schoolgirls in India. Acta Scientific Paediatrics, 3, 24-30.

Shrivastava Y., and Jagdev P., (2019). A Study to assess the effectiveness of selfinstructional module on knowledge regarding polycystic ovarian syndrome among B. Sc. Nursing students of Selected nursing college, Asian Journal of Nursing Education and Research, 9(3), 388-390.

Sowmya D ., Anitha S., (2017). Clinical study of polycystic ovarian syndrome (PCOS) in tertiary care centre, Int J Reprod Contracept Obstet Gynecol;6(8):3247-3251.

Starr R., (2017). Association between hispanic parents' attitudes and knowledge regarding obesity and their Children's body mass index: implications for the development of obesity, The University of Texas Rio Grande Valley. ProQuest Dissertations Publishing, 10607004. Available at: https-www-proquestcom.mplbci.ekb.eg/docview/2014472632.

Tay C.T., Hart R.J., Hickey M., Moran L.J., Earnest A., Doherty D.R., Teede H.J., and JohamA.E., (2020). Updated adolescent diagnostic criteria for polycystic ovary syndrome: impact on prevalence and longitudinal body mass index trajectories from birth to adulthood, BMC Medicine, 18:389: https://doi.org/10.1186/s12916-020-01861-X

Teede H.J., Misso M.L., Costello M.F., Dokras A., Laven J., Moran L., Piltonen T., Norman R.J., (2018). International PCOS Network. Recommendations from the international evidence-based guideline for the assessment and management of polycystic ovary syndrome, Clin Endocrinol (Oxf);89:251-268.

Upadhye J.J., Shembekar C.A., (2017). Awareness of PCOS (polycystic ovarian syndrome) in adolescent and young girls. Int $\mathbf{J}$ Reprod Contracept Obstet Gynecol,6: 22972301.

Witchel S.F., Oberfield S.E. and Peña A.S., (2019). Polycystic ovary syndrome: pathophysiology, presentation, and treatment with emphasis on adolescent girls. Journal of the Endocrine Society, 3(8):1545-1573 


\section{معلومات وإتجاهات فتيات المراهقه المتأخرة تجاه متلازمة تكيسات المبيض}

\section{أمبرة ححمـ رضاـ أمل أحمد حسن عمران - هند عبد الله السيد عفيفيـ أميرة ححمد سلامه}

يعتبر نقص المعرفة تجاه بمتلازمة تكيسات المبيض وسوء خيار ات نمط الحياة من العو امل الرئيسية المؤدية إلى متلازمة تكيسات المبيض. لذا كان الهدف من هذه الدر اسة هو تقييم معلومات و اتجاهات فتيات المر اهقه المتاخره تجاه متلازمة تكيسات المبيض. حيث تم اجر اء هذه الدراسة في المعهد الفني للتمريض بجامعة بنها على وبr مر اهقة. واظهرت النتائج ان أكثر من نصف فتيات المر اهقه المتاخرة لديهن وعي غير مرضي حول متلازمة المبيض المتعدد الكيسات. كان لاى أكثر من نصف فتيات المراهقه المتاخرة لديهن اتجاه سلبي تجاه متلازمة تكيسات المبيض. كان هناك ارتباط إيجابي بين الوعي الكلي والاتجاه الكلي تجاه متلازمة تكيس المبيض. واوصت الدر اسه بتنفيذ برنامج تثقيفي حول عوامل الخطر والتدابير الوقائية لمتلازمة تكيسات المبيض لدى الفتيات المر اهقات. 